\section{Category}

Synthesis of

Materials and

Unnatural Products

\section{Key words}

carbaporphyrins

fulvenes

indenes

\title{
Nitrogen-Free [18]Porphyrinoids in Two Steps
}<smiles>C1=CC(CC2=CCc3ccccc32)c2ccccc2C1</smiles>

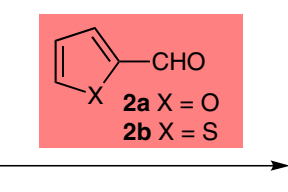

$\mathrm{KOH}, \mathrm{MeOH}$, reflux, $16 \mathrm{~h}$
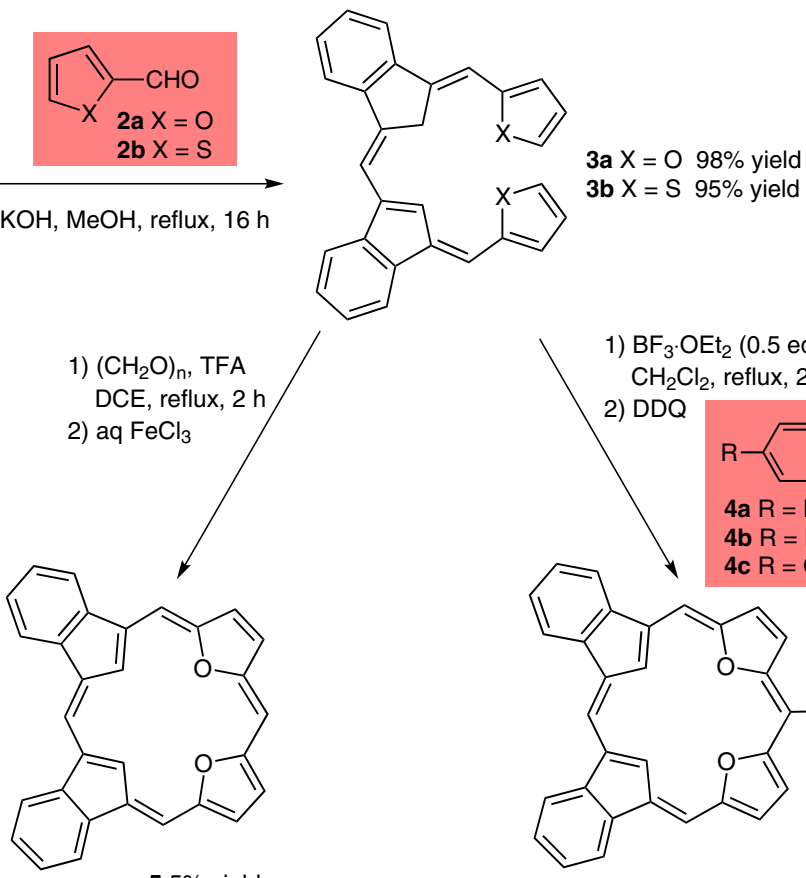

$55 \%$ yield

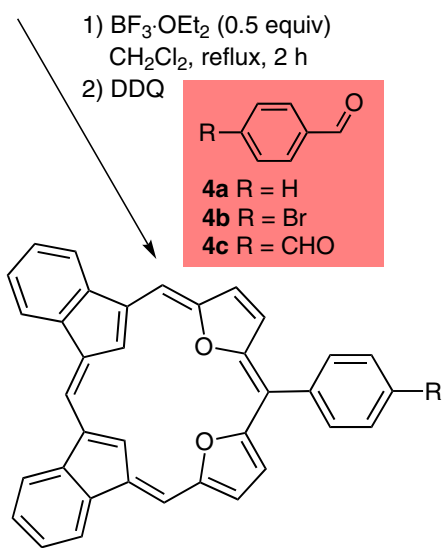

$6 a \mathrm{R}=\mathrm{H} \quad 39 \%$ yield

6b $\mathrm{R}=\mathrm{Br} \quad 40 \%$ yield $6 c \mathrm{R}=\mathrm{CHO} \quad 15 \%$ yield
Significance: The researchers synthesized substituted and unsubstituted dioxadicarbaporphyrins, which are the first examples of porphyrinoids with adjacent indenes. Bis(3-indenyl)methane $\mathbf{1}$ was reacted with various aryl aldehydes to yield compounds $\mathbf{3}$. Reaction with formaldehyde or an aryl aldehyde followed by oxidation led to the formation of dioxadicarbaporphyrins $\mathbf{5}$ and $\mathbf{6}$, respectively. These bilin analogues are interesting as natural products as well as organic opto-electronic materials.
Comment: The reaction of bis(3-indenyl)methane 1 with aryl aldehydes was expected to give a symmetric difulvene; however, the fully conjugated derivative $\mathbf{3}$ was obtained instead and confirmed with 2D NMR and $X$-ray crystallography. The ${ }^{1} \mathrm{H}$ NMR spectra of the porphyrinoids 5 and $\mathbf{6}$ displayed that the macrocycles are diatropic, as expected from the [18]annulene core. 